\title{
Radiological protection and biological COVID-19 protection in the nuclear medicine department
}

\author{
Kazunobu Ohnuki ${ }^{1} \cdot$ Mitsuyoshi Yoshimoto $^{1}$ (D) Hirofumi Fuji ${ }^{1}$ (D)
}

Received: 7 September 2020 / Accepted: 30 September 2020 / Published online: 10 October 2020

(C) Springer-Verlag GmbH Germany, part of Springer Nature 2020

Dear Sir,

Currently, coronavirus disease 2019 (COVID-19) is spreading worldwide. Healthcare workers are at risk of infection with this virus, and they must undertake biological protection measures. For those working in the field of nuclear medicine, radiological protection against unsealed radioactive materials is also important. Some procedures for this radiological protection are similar to those for biological protection from COVID-19. In fact, Vigne et al. [1] wrote a letter to the editor in which they compared the radiological risk with the COVID-19 risk and their results are summarized in Table 1 of this letter. The three rules for radiological protection - time of exposure, distance, and shielding - are also important for protection against COVID-19, and the authors interestingly described similar individual protective equipment for these two kinds of risks. However, the procedures for protection against each threat are not the same. Although Vigne's group simply mentioned the material products for shielding, the materials should also be considered carefully.

In the same issue of Vigne's letter, Assadi et al. [2] published an interesting editorial article. They explained how to use personal protective equipment (PPE), which is compatible with individual protective equipment, as in Vigne's letter, under the pandemic situation of COVID19. Assadi's group indicated that gloves should be put on last and removed first. Since hands are most commonly contaminated by viruses, this instruction is quite reasonable, and the same scenario is established for protection from contamination by unsealed radionuclides.

This article is part of the Topical Collection on Miscellanea

Hirofumi Fujii

hifujii@east.ncc.go.jp

1 Division of Functional Imaging, Exploratory Oncology Research and Clinical Trial Center, National Cancer Center, 6-5-1 Kashiwanoha, Kashiwa 277-8577, Japan
However, the type of gloves should also be carefully selected according to the objects to be protected against. In Assadi's editorial, the characteristics of four kinds of gloves made of different materials are shown in Table 1. The authors cited the report posted by the Center for Infectious Disease Research and Policy (CIDRAP). The best gloves for healthcare workers are first latex, and second nitrile. Although this principle is appropriate for protection from viral infection, it is not always suitable for protection from unsealed radioactive materials.

Recently, we evaluated the contamination induced by ${ }^{211} \mathrm{At}$, which is a promising alpha emitter applicable to targeted radionuclide therapy and is popular in Japan because of its availability. Alpha emitters must be strictly controlled owing to their toxicity. However, alpha particles can easily be shielded using thin materials such as paper, plastic films, and rubber sheets; therefore, protection against alpha emitters is generally uncomplicated. However, this is not the case for ${ }^{211} \mathrm{At}$, especially for the ${ }^{211}$ At anion. Lindencrona et al. [3] reported that the free ${ }^{211}$ At radionuclide can easily volatilize and, as a result, contaminate the environment. Moreover, our experiments using $\left[{ }^{211} \mathrm{At}\right] \mathrm{NaAt}$ solution demonstrated that the ${ }^{211} \mathrm{At}$ anion can penetrate latex gloves more easily than nitrile ones. In these experiments, we covered a piece of filter paper using a piece of latex glove or nitrile glove. Then, we dropped $50 \mu \mathrm{L}$ of a $1 \mathrm{MBq}\left[{ }^{211} \mathrm{At}\right] \mathrm{NaAt}$ solution onto pieces of the rubber gloves. After $3.5 \mathrm{~h}$, which is half of the half-life of ${ }^{211} \mathrm{At}$, we picked up the pieces of filter paper and their autoradiograms were obtained (Fig. 1). These findings suggested that nitrile gloves are advantageous over latex gloves during experiments with ${ }^{211}$ At compounds. This is a good example of a reduction of both radiological and biological risks.

Currently, nuclear medicine staff must protect themselves from two different risks - radiological and biological — simultaneously. We must therefore endeavor to find the best solution depending on the types of radionuclides used. 
Fig. 1 Penetration of $\left[{ }^{211} \mathrm{At}\right] \mathrm{NaAt}$ solution in pieces of the rubber gloves. a Photographs of pieces of filter papers covered by a piece of latex or nitrile glove. A droplet containing [ $\left.{ }^{211} \mathrm{At}\right] \mathrm{NaAt}$ was applied to each piece of the rubber glove. b Schemes of the photographs. c, d The autoradiograms of pieces of filter papers placed under the pieces of the rubber gloves. High activity was detected in the filter paper placed under the latex glove. Only slight activity was detected in the paper under the nitrile glove. The right image (c) is shown on a full scale and the left image (d) is an overexpressed one a
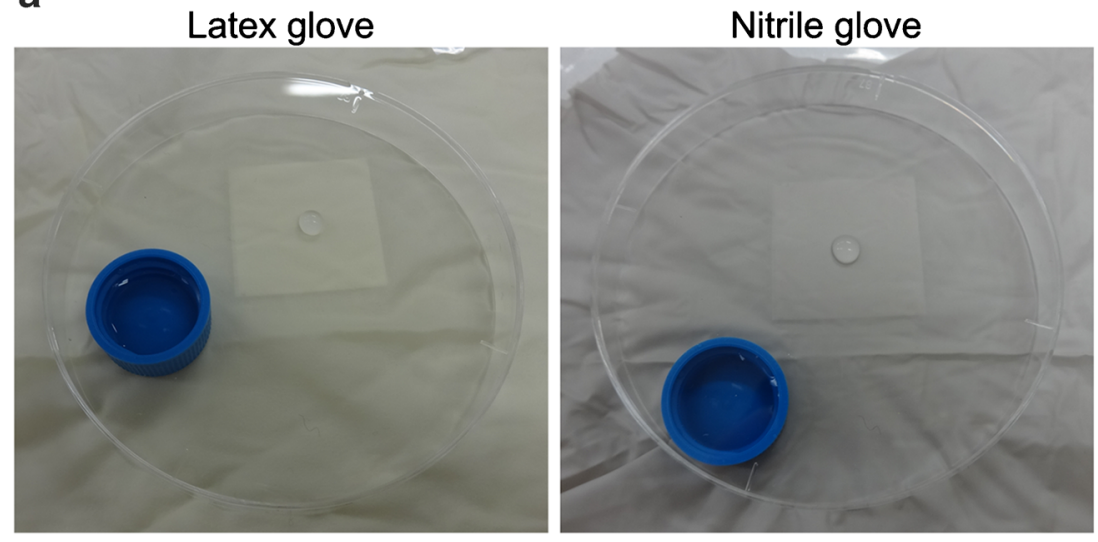

b
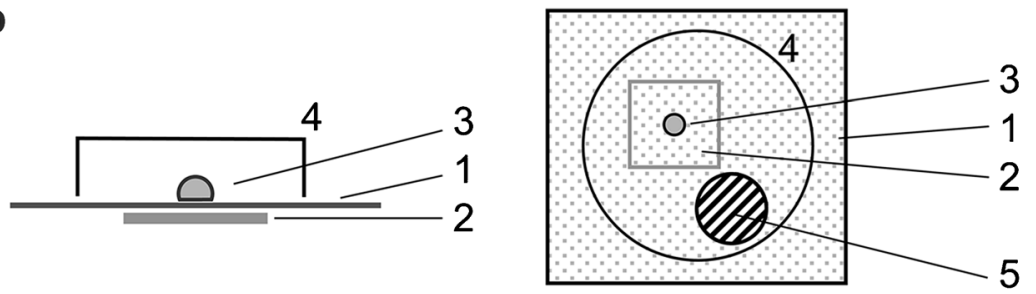

1: rubber, 2: filtering paper, 3: radioactive drop, 4: plastic plate (to avoid contamination by volatilized radionuclides) , 5: water (to avoid vaporization of drop)

c
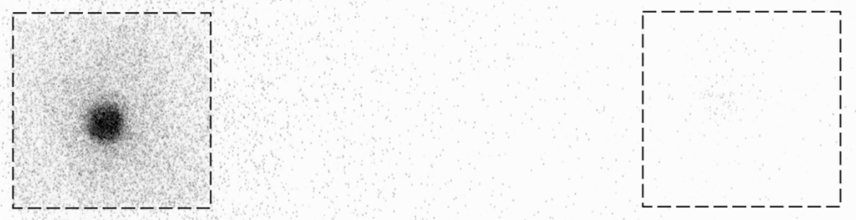

Latex

Nitrile

d

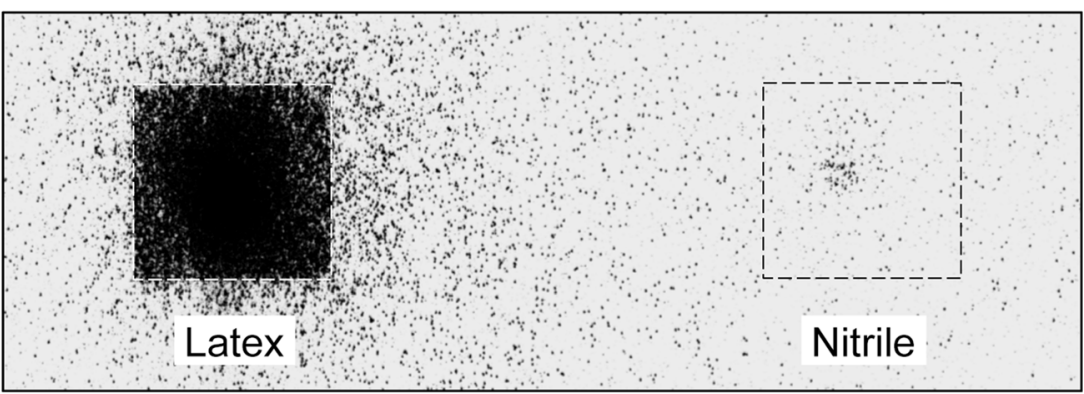


Author contributions All authors contributed to the study conception. The first draft of the manuscript was written by Kazunobu Ohnuki and Hirofumi Fujii, and all authors read and approved the final manuscript.

\section{Compliance with ethical standards}

Conflict of interest The authors declare that they have no conflicts of interest.

Ethics approval Not applicable since this study did not involve human participants or animals.

\section{References}

1. Vigne J, Aide N, Peyronnet D, Nganoa C, Agostini D, Barbey P. When nuclear medicine radiological protection meets biological
COVID-19 protection. Eur J Nucl Med Mol Imaging. 2020;47(8): 1802-5. https://doi.org/10.1007/s00259-020-04806-x.

2. Assadi M, Gholamrezanezhad A, Jokar N, Keshavarz M, Picchio M, Seregni E, et al. Key elements of preparedness for pandemic coronavirus disease 2019 (COVID-19) in nuclear medicine units. Eur J Nucl Med Mol Imaging. 2020;47(8):1779-86. https://doi. org/10.1007/s00259-020-04780-4.

3. Lindencrona U, Sillfors-Elverby L, Nilsson M, ForssellAronsson E. Adsorption and volatility of free ${ }^{211}$ At and ${ }^{125} \mathrm{I}$. Appl Radiat Isot. 2005;62(3):395-403. https://doi.org/10.1016/ j.apradiso.2004.07.004.

Publisher's note Springer Nature remains neutral with regard to jurisdictional claims in published maps and institutional affiliations. 